\title{
ELECTROCHEMICAL SURFACE PLASMON RESONANCE MEASUREMENT IN A MICROLITER VOLUME FLOW CELL FOR EVALUATING THE AFFINITY AND CATALYTIC ACTIVITY OF BIOMOLECULES
}

\author{
Ryoji KURITA $^{1, *}$, Yoshimi YOKOTA ${ }^{1}$, Akio UEDA $^{2}$ and Osamu NIWA ${ }^{1,2}$ \\ ${ }^{1}$ National Institute of Advanced Industrial Science and Technology (AIST) \\ Tsukuba Central 6, 1-1-1 Higashi, Tsukuba, Ibaraki, Japan \\ 2 Tokyo Institute of Technology, 4259 Nagatsuta, Midori-ku, Yokohama, Japan
}

\section{Film thickness measurements using an atomic force microscope}

Figure S-1 shows the SPR sensorgram when repeating the alternating injection process, and the height profile between the modified and unmodified gold surfaces using the atomic force microscope. We realized that the average thicknesses of the layered films formed in 2 and 8 cycles were 11.9 and 60.8 nm, respectively. 


\section{Cycles 8 Cycles}

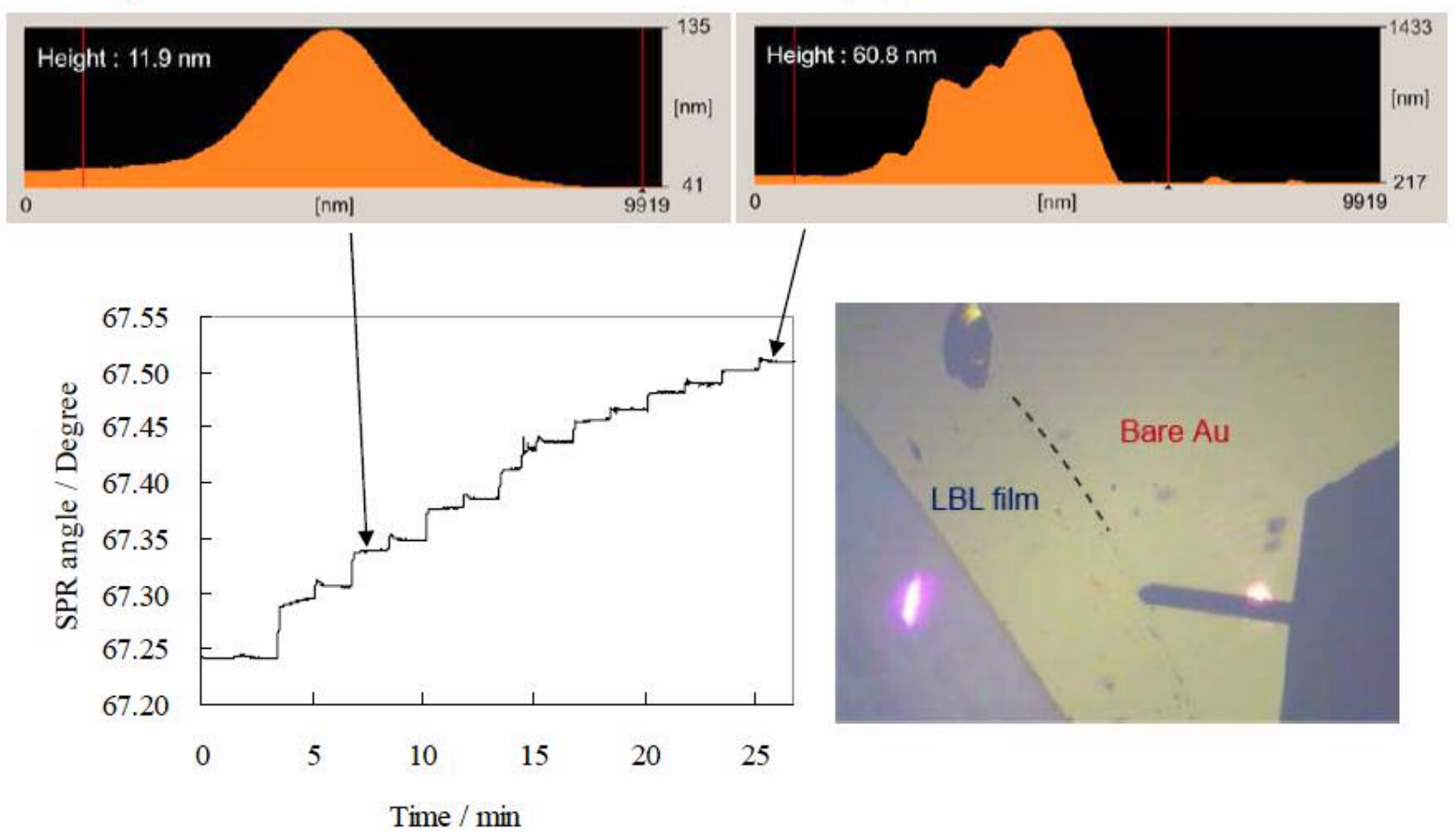

Figure S-1 The height profiles between the modified and unmodified gold surfaces using the atomic force microscope. 